\title{
NITRATES AND NITRITES IN ORAL CAVITY
}

\author{
Vl. Panov ${ }^{1 *}$, M. Balcheva ${ }^{1}$, A. Kisselova ${ }^{2}$ \\ ${ }^{1}$ Faculty of Dental Medicine, Medical University, Varna, Bulgaria \\ ${ }^{2}$ Faculty of Dental Medicine, Medical University, Sofia, Bulgaria
}

\section{SUMMARY:}

Nitrates' or nitrites' presence in saliva may lead up to many positive physiological effects. Salivary nitrates possess anti-inflammatory properties on the oral cavity and the digestive tract. Patients with periodontitis have lower concentration of $\mathrm{NO}_{2}$ in saliva than the healthy ones. In studies of the amount of salivary nitrates and nitrites, Streptococcus mutans and Lactobacillus spp., the number of caries in children is significantly reduced in patients with higher levels of salivary nitrates. Nitrites' concentration in vitro, equal to that in saliva, provokes cytolytic and cytostatic effect on the six major pathogens in the mouth. Studies on Streptococcus mutans show that the amount of nitrite and / or the production of NO are important for the survival of $\mathrm{S}$. mutans in the mouth. The growth of this microbe, a major pathogen of dental caries, is suppressed in the presence of physiological amount of nitrites in saliva.

We are looking for relation between the nitrates and different aspects of oral status.

Key words: nitrates, nitrites, saliva

AIM: To evaluate the presence of nitrates or nitrites in saliva specimens and look for relation between the the presence of nitrates or nitrites and different aspects of oral status.

\section{MATERIAL AND METHODS:}

173 specimens from the oral cavity (saliva) of 173 patients were evaluated by dry tests for rapid evaluation of nitrites. All the specimens were made on the dorsal surface of the tongue. Express dry testing gave us an opportunity to determine the instantaneous quantity of nitrate ions in the saliva

Tab. 1. Nitrites - percentage in all persons according to different values of dry tests.

\begin{tabular}{|l|l|l|}
\hline Rank & Value & $\mathbf{\%}$ \\
\hline 0 & - & $30,7 \%$ \\
\hline 1 & + & $27,4 \%$ \\
\hline 2 & ++ & $27,4 \%$ \\
\hline 3 & +++ & $14,5 \%$ \\
\hline Total & & $100,0 \%$ \\
\hline
\end{tabular}

\section{RESULTS AND DISCUSSUION:}

Groups of people with no trace of nitrites, with little and moderate values, were almost equal(Table 1), while $15 \%$ had a significant amount of nitrites. $69.3 \%$ of all patient had nitrites in saliva.

Patients with positive tests for nitrites in the oral cavity smoke about $20 \%$ more cigarettes per day, have larger number of extractions and more protein and blood in their saliva. In the subjects, negative for nitrites, we register more crowns, higher levels of gingival bleeding index and $\mathrm{OHI}$ of Green and Vermillion (Fig. 1).

Figure 1. Oral status and presence or absence of nitrites in the oral cavity.

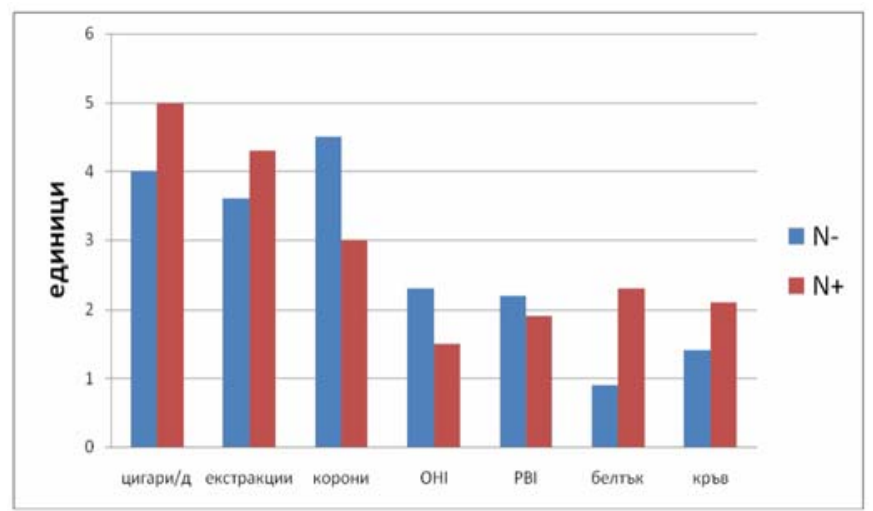

\section{CONCLUSION:}

The presence of nitrites in the mouth is associated with better oral hygiene status, and slighter inflammation of papillas. This confirms to some extent the research on this domain.

We found no differences on the number of caries.
Address for correspondence: Vl. Panov, DM Faculty of Dental Medicine, Medical University, Varna, Bulgaria Mobile: $+359 / 888567657$ e-mail: vl_panov@abv.bg 